\title{
O PROCESSO DA FORMAÇÃO DE PROFESSORES EM EDUCAÇÃO ESPECIAL E A PRÁXIS PEDAGÓGICA NO ATUAL CONTEXTO EDUCACIONAL BRASILEIRO
}

\author{
Hellyegenes de Oliveira ${ }^{1}$ \\ Francisco Marcos da Silva Figueiredo ${ }^{2}$
}

\begin{abstract}
RESUMO
O processo de formação de professores viabiliza diversos contextos desde o período colonial até a contemporaneidade nos mais diversos aspectos, sejam eles sociais, culturais ou políticos. Neste processo, destacam-se alguns tópicos a suscitar-se na referente pesquisa, dentre as quais se abordam a educação especial e a significação dos alunos, definindo o termo incluir dentro das escolas regulares e as abordagens pedagógicas para receber esse público. Em processo de finalização foram discutidas as ações e métodos de incentivos à construção das práticas de docentes, o que levaram a uma reflexão do atual cenário na qual a educação inclusiva está inserida, buscando soluções coerentes e possíveis dentro da reforma escolar, analisando quais são os aspectos e as propostas para efetivação da atuação do professor na área da educação especial. Trata-se de um estudo de natureza exploratória com abordagens qualitativas. O citado tema é polêmico, atual e transversal, tem sua base fundamentada na Constituição Federal de 1988, sendo um direito de todos a acessibilidade e igualdade a educação, porém, o cenário atual apresenta contradição no que diz respeito a estrutura física e curricular. Constata-se, ainda, que a formação dos docentes deixa a desejar e a raiz do pensamento social e cultural está imerso numa falsa ideologia inclusiva.
\end{abstract}

Palavras-chave: Formação de professores. Educação especial. Inclusão. Práxis.

\section{INTRODUÇÃO}

A formação de professores começou tardiamente em nosso país. As primeiras escolas com esse intuito passaram por um processo de abertura e fechamentos das instituições, por se tratar de um período ainda em que a maioria da população morava na zona rural e eram analfabetas. Só a partir da industrialização que se concretizou a implantação das escolas para formar docentes. Atualmente, enfatiza-se a formação de profissionais qualificados, reflexivos e críticos para atender o ensino centrado nos alunos. Para que isso ocorra é necessário treinar e formar professores dentro dos princípios discutidos nos âmbitos políticos, social e educacional.

Segundo Werneck (1993), evoluir é perceber que incluir não é tratar igual, pois todos somos diferentes e aprendizes com necessidades especiais terão oportunidades diferentes. A partir desse conceito, os resultados alcançados terão meios diferentes com os mesmos objetivos. Incluir é abandonar o estereótipo.

\footnotetext{
${ }^{1}$ Especialista em Psicopedagogia e EJA. Mestrando em Educação pela Universidade do Sul de Santa Catarina (UNISUL). E-mail: hellyegenes@ hotmail.com

${ }^{2}$ Especialista em Auditoria em Saúde e mestrando em Saúde Coletiva da Universidade Católica de Santos (UNISANTOS). E-mail: maarcos2811@gmail.com
} 
A educação inclusiva é, acima de tudo, um projeto em andamento que tem como base a igualdade de direitos e acessibilidade de todos, independente de condições socioeconômicas, religiosas, etnoculturais, e de deficiências físicas ou psicológicas. Trata-se de uma ordem moral intransferível da sociedade contemporânea. A educação inclusiva na nossa sociedade é relevante, pois garante os maiores bens da coletividade, que são o conhecimento e a cultura, e é por meio da educação que podemos mudar e inserir novos conceitos que ficarão para as gerações futuras.

A inclusão é um movimento no qual os familiares das pessoas com deficiência buscam seus direitos na sociedade e uma vida menos preconceituosa, sabendo que é compromisso de todos melhorarem a qualidade de vida dos alunos. As escolas devem estar preparadas para receber os educandos com necessidades especiais, certificando uma educação de qualidade para os mesmos, de acordo com a Resolução $n^{\circ}$ 2/2001 que instituiu as Diretrizes Nacionais para a Educação Especial.

Nos últimos anos, as políticas educacionais de formação voltadas para educação especial passaram por transformações. No entanto, há uma necessidade de melhorar a qualificação do professor, tendo como um dos indicadores a oferta de formação continuada de médio e longo prazo, pois em alguns casos a graduação deixa lacunas tornando necessária a revisão de conceitos.

Não há como incluir crianças com necessidades educativas especiais nas instituições sem antes haver um processo de qualificação de apoio aos docentes, assim como garante a Lei 7.853, de 24 de Outubro de 1989, que dispõe sobre o apoio às pessoas portadoras de deficiência e sua integração social, além de definir como crime recusar, suspender, adiar, cancelar ou extinguir a matrícula de um estudante por causa de sua deficiência, em qualquer curso ou nível de ensino, seja ele público ou privado. A pena para o infrator pode variar de um a quatro anos de prisão, mais multa.

É preciso refletir quando esse assunto é abordado. O educador tem que compreender os contextos social e histórico da exclusão e a proposta de inclusão. O mesmo tem que ter experiência e informações necessárias para se aproximar e atuar de forma correta, pedagogicamente falando, pois sabemos que os mesmos sentem-se inseguros ao receber estes alunos. Neste novo cenário em que as instituições tentam se moldar para ter um ambiente favorável à inclusão, é relevante indagar quais foram os avanços e as dificuldades que os professores viveram e ainda vivenciam para tornar possível a educação inclusiva. Em geral, os profissionais se encontram em condições desfavoráveis de trabalho, pois o ambiente esta superlotado, com escassez de materiais didáticos, ausência de recursos tecnológicos e professores com a capacitação inadequada para atender a necessidade dos alunos com deficiência. Apesar da rede de ensino público ter avançado no Brasil 
no quesito acesso, é necessário e preciso investir na capacitação de professores em educação inclusiva.

Para Kauark et al. (2010), as características da pesquisa exploratória são ainda superficiais sobre uma determinada temática, uma vez que a função é buscar um aprofundamento a fim de tornar o conhecimento do devido tema mais evidente. Segundo Zikmund (2000), os estudos exploratórios, frequentemente, são de utilidade, pois descrevem minuciosamente uma determinada situação, exploram alternativas e descobrem novas ideias.

Este estudo procura esclarecer e definir a origem de um problema e gerar mais informações para desenvolver pesquisas futuras conclusivas. $\mathrm{O}$ pesquisador pode ter algum conhecimento no tema, porém essa pesquisa será útil para o mesmo fato organizacional, isto porque pode haver inúmeras alternativas explicativas, dessa forma o pesquisador terá conhecimento, se não de todas, pelo menos de algumas delas. A pesquisa qualitativa foi escolhida por descrever a complexidade de um determinado tema, analisar a interação de certas inconstantes, entender e classificar os processos dinâmicos vivenciados por determinado grupo social.

Na pesquisa qualitativa, o objetivo e a subjetividade do sujeito são indissociáveis, dessa forma imensuráveis (PRODANOV; FREITAS, 2013). Para Gil (1999), o uso dessa abordagem evidencia o aperfeiçoamento da investigação dos quesitos relacionados a esses fenômenos e de suas relações mediante a máxima valorização da situação estudada, buscando o que era comum, mais permanece aberta para perceber a singularidades e os significados múltiplos.

\section{A EDUCAÇÃO ESPECIAL E A SIGNIFICAÇÃO DA APRENDIZAGEM DOS ALUNOS}

A educação inclusiva é um tema de debate atual, polêmico e transversal. Este tema tem sido pauta de várias conferências, simpósios e congressos no meio acadêmico, sendo um assunto de importância coletiva devido seu caráter de universalização, democratização e pluralidade; abarcando no cenário atual os diversos âmbitos executivo, legislativo e jurídico; e um grupo muito diverso da sociedade, como profissionais da saúde, educação, juristas, e a própria camada de pessoas com necessidades especiais, todas estão engajadas por uma luta e com único objetivo de fazer valer os direitos de todos.

Não há educação sem professor. O professor tem o papel primordial quando se fala em educação, pois juntamente com os alunos, são os protagonistas de um sistema que gera crescimento, cultura e desenvolvimento de toda a nação. No cenário atual da educação, existe uma base curricular para a formação de professores do ensino comum e seu alicerce tem lacunas vazias, principalmente quando se fala em educação inclusiva, uma vez que, na raiz da sociedade, tem 
grupos diferentes do "padrão" que sofrem com a exclusão, desde a educação até a inserção destes na vida profissional.

O inquietante problema vivido pelos profissionais da educação tem levado estes a se engajarem na luta pela defesa de ensino e com isso desenvolverem projetos tendo em vista a busca de alternativas para superação. Estes profissionais precisam compreender o conceito que está em transformação, para que este processo de mudança seja possível. Portanto, é preciso rever as velhas ideologias para então organizar, planejar a solução deste conflito e é dever desses profissionais buscar condições e qualificação para assumir o papel que se trata as Leis e Normas da educação inclusiva. E é dever do Estado proporcionar os instrumentos, recursos, propostas e ambiente adequado a essa nova ideologia. A formação dos profissionais deve ter caráter continuado, isto é, a busca constante por conhecimento, seja através de atualizações, pesquisas e criações de novos métodos de aprendizagem.

A educação inclusiva é um movimento de caráter universal, que envolve ações em diversas dimensões: cultural, social, política e pedagógica, que teve como estopim o reconhecimento do paradigma inclusão/exclusão, levando a discussão dos direitos já previstos na $\mathrm{CF} / 88$, a qual prevê que a educação é dever do Estado e para todos, isto é, a democratização da educação, pois concluíram que a totalidade dos educandos aprendem, participam e tem um melhor desempenho quando estes estão juntos sem nenhum tipo de preconceito. E para entender as complexidades do sistema de ensino, foi necessário colocar em debate as práticas de discriminação e criar soluções eficazes para erradicá-las.

A sociedade contemporânea e as escolas foram "forçadas" a assumir o papel de inclusão. Apesar de muito se ouvir falar em democratização, o sistema educacional permanece excluindo indivíduos e grupos considerados "anormais". Assim, o Ministério da Educação/Secretaria de Educação Especial, tendo uma visão moderna de acordo com os debates sociais apresentou um documento elaborado com caráter jurídico com as propostas da nova Política Nacional de Educação Especial na perspectiva da Educação Inclusiva.

A Educação Especial é uma modalidade que ultrapassa por todas as etapas, níveis e modalidades do ensino básico, não caracterizando como reforço ou substituição da escolarização, pois os alunos devem estar frequentando o ensino da escola regular e complementando a escolarização, em turnos contrários. E ainda segundo a LDBEN, os alunos com necessidades especiais devem ser escolarizados em conjunto com seus pares não deficientes sob supervisão de um professor capacitado nas escolas regulares. Nos Atendimentos Educacionais EspecializadosAEE. No âmbito escolar, trouxe mudanças significativas tanto no que diz respeito à organização quanto na qualidade dos resultados obtidos. 
A Lei Federal n. 9394/96 e a Resolução CNE/CBE n. 02/2001 apontam para um currículo diferenciado e flexível ao público alvo da educação especial, porém, foi com a Política Nacional de Educação Especial na Perspectiva da Educação Inclusiva (BRASIL, 2008), que ocorreram as verdadeiras mudanças: conceitual e estrutural. Podemos destacar algumas mudanças tais como: transversalidade da educação especial desde a base até a vida acadêmica; educação com atendimento especializado; formação de docentes com a visão inclusiva e com práticas na especificidade do aluno, para que este seja melhor integrado; interação da família, comunidade e escola; articulação intersetorial para implantar as políticas públicas e acessibilidade desde a estrutura física, equipamentos, transporte, comunicação e informação.

O AEE promove autonomia e independência aos alunos dentro e fora da escola. Utilizam instrumentos que possibilitam o acompanhamento, monitoramento e avaliação ao longo do processo de aprendizagem. Na Educação Infantil, o AEE encoraja o desenvolvimento precoce, que tem por função maximizar o desenvolvimento e aprendizagem dos estudantes. De maneira integral, engloba todas as modalidades da educação básica, sendo uma oferta obrigatória da instituição de ensino. $\mathrm{O}$ atendimento educacional especializado, em alguns casos específicos como alunos surdos-mudos, é ofertado tanto na categoria oral e escrita quanto na Língua de Sinais.

\section{AÇÕES E MÉTODOS DE INCENTIVO A CONSTRUÇÃO DAS PRÁTICAS DE FORMAÇÃO DE PROFESSORES EM EDUCAÇÃO ESPECIAL}

Por ser um tema atual e polêmico, a inclusão da pessoa deficiente no âmbito educacional exige uma organização no Projeto Político Pedagógico - PPP para que as peculiaridades inerentes a este público e as barreiras sejam trabalhadas no contexto escolar. Segundo Cavalcante et al (2012), ao pensar na inclusão deve-se ter uma reflexão do que é incluir na realidade do contexto educacional. Incluir significa inserir totalmente este aluno no cenário escolar; e a escola legaliza como instituição - as práticas pedagógicas e de formação dos seus aprendizes, rompendo assim, essa cadeia cultural do paradoxo inclusão/exclusão e adota meios para assegurar os direitos de aprendizagens de todos, tais meios variam da necessidade de cada aprendiz, da criatividade, observação e experiência do professor, e este profissional deve ser dotado de humanidade e perspicácia, sua formação inicial deverá ser continuada.

A inclusão é orientada pelas diferentes práticas pedagógicas num mesmo ambiente para que o aprendiz com alguma deficiência consiga acessar o objeto do seu desenvolvimento e crescimento. É necessário saber que o aluno deverá ter acesso a todos os instrumentos e por todas as vias, chegando às metas esperadas e banindo todos os obstáculos existentes. O docente deverá 
buscar os conhecimentos em vias alternativas tais como: jogos, brincadeiras e mais diversas estratégias para repassar e chegar ao objetivo proposto.

O currículo hoje é considerado a base estrutural do qual faz com que as ações sejam dinâmicas e sistematizadas de acordo com os esforços pedagógicos. É de relevância citar que estes currículos são planejados pelos próprios professores e elaborados do ponto de vista multicultural, isto porque o âmbito escolar abrange uma diversidade étnica, social e cultural. Ao centrar na educação inclusiva, os currículos tornam-se mais convergentes às práticas de inclusão daqueles antes excluídos desse cenário, que por conveniência as velhas práticas e hábitos, acabaram tendo a função de manter a escola sem as mudanças necessárias para essa nova visão de incluir, estagnando em um sistema antigo e inadequado as novas propostas do PNE e da LDBEN.

É importante entendermos que incluir não significa o empobrecimento dos conteúdos básicos da grade curricular e muito menos quando o aluno com deficiência é parte integrante de sistema educacional. Os currículos não devem ser entendidos como um documento alternativo ou um sistema paralelo de ensino, pois incluir significa fazer parte do todo. A escola inclusiva é uma pequena parte de um projeto maior, isto é, a sociedade precisa assumir seu papel na construção de cidadãos críticos e reflexivos, então deve ser uma preocupação não só dos profissionais e pesquisadores na área de educação.

Segundo Barbosa (2003), é de relevância a participação da sociedade nesse projeto de inclusão escolar porque a educação é a via mais segura para todos, principalmente para aquelas pessoas que convivem com a exclusão É através da educação que teremos a formação de uma nova geração de cidadãos, com um novo raciocínio e atitudes comportamentais inclusivas. A formação de docentes de ensino comum na perspectiva inclusiva é ponto chave de debate, pois estes profissionais são protagonistas que desempenham o papel importante para construir cidadãos com mentalidade inclusiva e sua contribuição é significativa nesse grande projeto.

Para Omete (1995), os docentes do ensino comum precisam ter trânsito livre para o sistema de ensino especial, portanto esses professores precisam receber, na sua formação inicial ou em especializações, conhecimentos básicos sobre alunos com deficiências, os métodos, instrumentos e recursos voltados para esse grupo, pois só assim esses profissionais serão qualificados para exercer em salas comuns com a presença de alunos especiais. Os professores precisam de uma formação sólida, científica, sistematizada e qualificada para ser considerado um bom profissional, assim a sua teoria, prática e experiência no campo são recursos a serem utilizados para atender alunos com necessidades educacionais especiais.

Para exercer a sua formação, o professor deve buscar conhecimentos no exercício profissional e conhecimentos específicos na área de sua atuação, pois sua formação permitirá o 
aprofundamento de caráter interativo e interdisciplinar nas escolas regulares (BRASIL, 2008). Para assegurar a implementação das políticas públicas valorizando intersetorialidade, no seu currículo deve contemplar conhecimento de gestão de sistema, visando o desenvolvimento do projeto com os demais profissionais das outras áreas e a acessibilidade à estrutura e ações de caráter social, trabalho e justiça. Pode-se notar a importância do trabalho multiprofissional, integrando diversos setores. A escola, como dita anteriormente, é parte de um projeto maior, que o público alvo deve ser o maior beneficiado dos seus programas e projetos, portanto, todo grupo profissional que exerce as intervenções deve cumprir os princípios constitucionais que preveem a igualdade de condições para manter o acesso e a permanência e a continuidade em todos os níveis de educação.

É relevante expressar que o professor tem um papel elementar na construção da educação inclusiva porque cabe a ele uma parcela expressiva nesse grande projeto. É bom destacar a tentativa de dissociação entre a formação de professor de ensino comum e do professor de ensino especial, pois, de acordo com Omete (1995), houve grandes debates na década de 80, nos Estados Unidos, pois alguns críticos apontavam a mesma responsabilidade de ambos os sistemas pela educação dos alunos especiais. Por isso, podemos afirmar que a formação do professor deve ter uma base sólida, no que diz respeito às questões e os recursos que podem ser aplicados na educação inclusiva. Em 11 de setembro de 2001, foi estabelecida a resolução CNE n.2, no artigo 18:

São considerados professores especializados em educação especial aqueles que desenvolveram competência para identificar as necessidades educacionais para definir, implementar, liderar e apoiar a implementação de estratégias de flexibilização, adaptação curricular, procedimentos de didáticos pedagógicos e práticas alternativas, adequados ao atendimento das mesmas, bem como trabalhar em equipe, assistindo professor de classe comum nas práticas que são necessárias para promover a inclusão dos alunos com necessidades educacionais especiais. (BRASIL, 2001).

Esta Resolução definiu a função e o perfil dos professores da educação especial e aponta como alternativa, a licenciatura em educação especial ou em uma de suas áreas. O problema ainda persiste na história em formar e organizar a atuação dos professores na área de comprometimento. Para Ferreira (1999), é necessário abandonar a formação de docentes em categorias ou comprometimentos, isto é, cegos, surdos, deficientes mentais e autistas, entre outros. No IV Congresso Estadual Paulista, em maio de 1996, a formação de educadores foi alvo de debates. Para uns, a ideia de que a tradição e a legislação determinavam a formação e atuação do professor especialista por categoria de deficiência, é considerada inadequada, porque desse ponto vista cada categoria tende a ser olhada peculiarmente pela sua necessidade, assim teria demanda de recursos humanos, metodológicos, materiais de uso exclusivo daquela categoria; sendo contrário ao que diz a Lei de Diretrizes e Bases da Educação Nacional e a própria Constituição Federal (1988). 
De acordo com Omete (1995), a organização dos currículos e de serviços centrada na deficiência especifica é facilitada, pois contribui para um planejamento curricular e de serviços voltados para um melhor planejamento e desempenho da categoria específica, porém seria um problema utilizar as categorias como rótulos, isso porque é necessário ter critérios e cuidados com essas padronizações. Ainda segundo a autora, para que não ocorra o pecado do exagero com método de categorização, as semelhanças e as diferenças entre os integrantes das categorias não venha somente destacar como qualidades centrais as deficiências das pessoas portadoras de necessidades especiais, criando uma falsa ideia de semelhança e igualdade entre o que de fato é uma realidade social e natural da categoria.

Na educação inclusiva é indicado o critério e cuidado em duas ocasiões. Na primeira, quando o paradigma da inclusão não interessar as características gerais, como física ou mental. Essas características não devem servir como definição e organização dessa categoria, podendo fazer uso quando tiver necessidade de um tratamento específico e diferenciado para um melhor desenvolvimento, então a organização do sistema de categoria é justificada. Na segunda ocasião, é na própria utilização dessas categorias. Para que sejam validadas, é necessário o seu embasamento em uma quantidade mínima de critérios, de maneira que evite a igualdade dentro da categoria, exceto quando se falar em adjetivos específicos.

Sabendo que a inclusão é uma questão política e didático-pedagógica, devemos pontuar que a tarefa das instituições de Ensino Superior não é apenas graduar docentes na perspectiva inclusiva, e achar que nas pesquisas encontraremos soluções didático-pedagógicas para alunos com necessidade educacional especial; isso porque a atividade de ensino e de pesquisa deve estar em sincronismo com elaboração de políticas públicas. Problemas de ordem política não podem ser resolvidos com pesquisas voltadas para área de Educação, apesar de que a nata intelectual do país é favorecida com ideias e planejamentos educacionais. Como exemplo, existe um intenso trabalho de programas de graduação e pós-graduação de pouca visualização da coletividade, a qual esses programas deverão alcançar. Somente com debate daqueles que vivem no contexto que o problema está inserido, sem utopias e uma margem de erro significativa, poderemos falar em inclusão definitiva.

\section{CONSIDERAÇÕES FINAIS}

A educação inclusiva está bem fundamentada, no arcabouço jurídico atual, tendo como fundamentos Decretos, Normas e Leis que legalizam que todas as escolas, desde 2016, tivessem em seus programas e projetos a inclusão de pessoas portadoras de necessidades especiais. Dessa forma, cumprindo o que está na Constituição Federal de 1988 e na LDBEN, para promover o 
acesso e igualdade de todos. Apesar de muitas teorias e debates, a inclusão não foi efetivada plenamente, pois é um desafio com a complexidade para além da área educacional, tendo o âmbito político, social, cultural que devem estar em sincronismo com todos os demais. O primeiro grande avanço para a educação especial é suprir todos os recursos para a concretização e implantação da educação inclusiva, desde os recursos humanos, métodos, materiais, aperfeiçoamento profissional continuado e práticas dentro da área da educação inclusiva.

Acima de tudo, é necessária uma modificação na raiz da sociedade, pois o professor tem um papel essencial, juntamente com a família e a sociedade, de agente transformador no que diz respeito à cultura e pensamento. Não podemos pensar em inclusão, sem antes sermos os protagonistas em incluir. É somente dessa forma que os objetivos propostos na Lei e Normas darão seus primeiros passos rumo ao sucesso da educação inclusiva. Apesar de muitos debates sobre inclusão, principalmente no âmbito educacional, esse tema ainda está obscuro, pois na leitura de alguns artigos percebemos a dificuldade de alguns profissionais para apontar ações que poderiam auxiliar na inclusão de alunos com necessidades especiais.

Para tanto, são necessárias atitudes imediatas - debates sinceros, coerentes e possíveis entre gestores, família, comunidade, escola - para que possam chegar a uma conscientização sobre as fragilidades e desafios que serão enfrentados pós-reforma, pois ainda há uma acomodação disfarçada socialmente, necessitando de uma reflexão profunda sobre o verdadeiro sentido de incluir.

A formação de professores, por ser de caráter continuado, precisa de uma base sólida, empírica e sistematizada, e os cursos superiores devem atentar que para formar profissionais capacitados e qualificados é necessário fornecer a prática aos discentes, que posteriormente chegam ao campo de trabalho sem uma experiência e qualificação adequada. A maioria dos profissionais que iniciam a sua vida profissional saindo direto do curso de graduação chega quase que zerados ao ambiente escolar, quando se fala em educação inclusiva, então é necessária uma especialização na área. Também, é necessário rever a grade curricular universitária, a qualificação dos docentes que saem do curso de Pedagogia para atuar num cenário complexo, que é o campo da Educação.

\section{REFERÊNCIAS}

BARRETO, K. C. C.; BARRETO, W. P. A formação dos professores e a inclusão escolar. Brasília: [s.l.]. Disponível em: https://ifgoiano.edu.br. Acesso em: 20 de fev. de 2020.

BRASIL, Conselho Nacional de Educação. Resolução CNE n.2, de 11 de setembro de 2001. Resolução que institui Diretrizes Nacionais para a Educação Especial na Educação Básica. Brasília. 
. Decreto Lei $n^{\circ}$ 8.530, de 2 de janeiro de 1946. Lei Orgânica do Ensino Normal. Disponível em: www.soleis.adv.br. Acesso em: 15 de março de 2020.

. Lei n 5.692/71, de 11 de agosto de 1971. Diário oficial da União, Brasília, 12 ago. 1971.

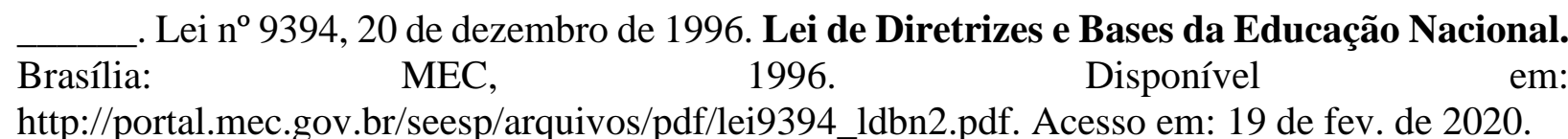

Parecer 349-72. Documento, n. 137, p. 155-173, abr. 1972.

. Marcos Politico-Legais da Educação Especial na Perspectiva da educação Inclusiva.

Secretaria de Educação Especial. Brasília: Secretaria de Educação Especial. 2010.

. Politica nacional de educação especial na perspectiva da educação inclusiva. Brasília: MEC/SEESP, 2008.

DUARTE, Sergio Guerra. Dicionário brasileiro de educação. Rio de Janeiro: Antares/Nobel, 1986.

FERNANDES, Cláudia, O.; FREITAS, Luiz Carlos. Indagação sobre currículo: currículo e avaliação. Brasília: MEC/SEB, 2007.

FERREIRA, M. C. C. Construindo um projeto politico-pedagógico para a formação de educadores no contexto da Educação Especial. In: BICUDO, M. A.V; SILVA JUNIOR, C. A. (Orgs.). Formação do educador e avaliação educacional. São Paulo: Ed. UNESP, 1999. v.2, p.139-148.

GIL, A. C. Métodos e técnicas de pesquisa social. 5. ed. São Paulo: Atlas, 1999.

GOTTI, M. O. Integração e inclusão: nova perspectiva sobre a prática da educação especial. In: MARQUESINE, M. C. et al. (Orgs.). Perspectivas multidisciplinares em Educação Especial. Londrina: editora UEL, 1998. p. 365-372.

KASSAR, M. C. M. Educação Especial na perspectiva da educação inclusiva: desafios da implantação de uma política nacional. Educar em Revista, Curitiba, n. 41, p. 61-79, jul./set. 2011.

KAUARK, F. S.; MANHÃES, F. C. \& MEDEIROS, C. H. Metodologia da pesquisa: um guia prático. Itabuna: Via Litterarum, 2010. Disponível em: http://www.pgcl.uenf.br/2013/download/livrodemetodologiapesquisa2010.pdf. Acesso em: 22 de fev. 2020.

PRODANOV, C. C.; FREITAS, E. C. de. Metodologia do trabalho científico: Métodos e Técnicas da Pesquisa e do Trabalho Acadêmico. 2. ed. Novo Hamburgo: Feevale, 2013. Disponível em: http://docente.ifrn.edu.br/valcinetemacedo/disciplinas/metodologia-do-trabalhocientifico/e-book-mtc. Acesso em: 10 de jan. 2020.

REIS FILHO, Casemiro. A educação e a ilusão liberal. 2. ed. Campinas: Autores Associados, 1998.

SÃO PAULO. Decreto 27, de 12/03/1890. In: Coleção da Leis e Decretos do estado de São Paulo. Tomo I- 1889-1891. São Paulo: Impressa oficial do Estado, 1909. 
TANURI, Leonor Maria. História da formação de professores. Revista Brasileira de Educação, n. 14, p. 61-88, maio/ago., 2000.

UNESCO. Declaração de Salamanca e Enquadramento na Área das Necessidades Educativas Especiais. Lisboa: Instituto de Inovação Educacional. 1994. Disponível em: http://portal.mec.gov.br/seesp/arquivos/pdf/salamanca.pdf. Acesso em: 05 de mar. de 2020.

WERNECK, Claudia. Ninguém mais vai ser bonzinho na sociedade inclusiva. Rio de janeiro: WVA, 1997.

ZIKMUND, W. G. Business research methods. 5.ed. Tx: Dryden 2000. 